\title{
SHOPPING CENTER: O Fenômeno e sua Essência Capitalista
}

\author{
GLAUCO BIENENSTEIN* \\ UNIVERSIDADE FEDERAL FLUMINENSE
}

Arquiteto, Doutor em Planejamento Urbano e Regional pelo IPPUR/UFRJ, Mestre em Geografia pelo IGEO/UFRJ, Professor da Escola de Arquitetura e Urbanismo da Universidade Federal Fluminense.

\section{Introdução}

Não há como negar que tanto a vida quanto a configuração do urbano brasileiro contemporâneo, especialmente o de grande porte, têm sofrido consideráveis modificações. Dentre elas destacam-se aquelas resultantes da presença de expressões do setor terciário tais como o comércio informal de rua, os prédios destinados a serviços especializados e os shopping centers.

Nas notas a seguir pretende-se contribuir para o entendimento tanto do fenômeno quanto da essência do shopping center ${ }^{l}$ enquanto importante objeto pertencente ao conjunto de elementos relacionados ao processo de reorganização contemporânea do capital que, por sua vez, tem transformado intensamente as cidades.

Para tanto, o texto se desenvolve em três partes. A primeira, de cunho histórico-genético, fornece algumas notas sobre a origem dos $\boldsymbol{S} . \boldsymbol{C}(\mathbf{s})$., indicando o contexto sócio-espacial que demandou seu surgimento. A segunda, de caráter teórico-conceitual, trata, através da teoria social de Marx, do fenômeno e da essência capitalista do mencionado objeto. Na conclusão, procura-se traçar um breve resumo sobre algumas repercussões dos $\boldsymbol{S}$. C(s). nas cidades, dentre elas, a criação de novas sociabilidades (modos de vida, de comportamento, atitudes, hábitos, relações sociais e uso cotidiano do espaço urbano).

Cabe ainda ressaltar que a gama de possibilidades de investigação conferida pela riqueza do objeto aqui tratado, sugere a explicitação prévia de alguns balizamentos teórico-metodológicos.

Nesse sentido, na medida em que as transformações no comércio ao longo da história não são aqui compreendidas fora do conjunto da produção social, considera-se importante destacar dois entendimentos:

(1) no capitalismo, um modo historicamente específico de controle do metabolismo social (MÉSZAROS, 1995: 41), os elementos resultantes da produção do espaço, antes de qualquer atributo singular, generalizam-se sob as feições e a estrutura da forma-mercadoria;

(2) tanto a proximidade do presente quanto a novidade dos fenômenos e aspectos aqui tratados, implicam a adoção de fontes peculiares como jornais e periódicos. A utilização de tais fontes, entendidas como elementos de observação empírica, permitiu não somente captar a imediaticidade dos fatos, fenômenos e aspectos relacionados ao objeto aqui estudado, o S.C., como também perceber em que medida as questões e problemas sobre a cidade têm extrapolado os limites das discussões entre especialistas, espraiando-se, através das mídias, no cotidiano das pessoas.

\footnotetext{
Algumas Notas sobre a Origem dos Shopping Centers

* Arquiteto, Doutor em Planejamento Urbano e Regional pelo IPPUR/UFRJ, Mestre em Geografia pelo IGEO/UFRJ, Professor da Escola de Arquitetura e Urbanismo da Universidade Federal Fluminense.

1 De agora em diante o termo shopping center será enunciado através da abreviação $\boldsymbol{S}$.C.
} 
Desde a Revolução Industrial, a história do desenvolvimento econômico tem apontado, de uma forma cada vez mais acelerada, na direção de uma divisão mundial do trabalho e de uma rede de fluxos e intercâmbios crescentemente complexa e especializada (HOBSBAWM, 1995: 92).

O surgimento e a proliferação do $\boldsymbol{S}$. $\boldsymbol{C}$., uma das formas de objetivação de ambiente construído destinado à comercialização e ao consumo de mercadorias, transcorreu no bojo da concentração espacial do capital. À progressiva mudança nas formas de organização, métodos e técnicas de produzir, correspondeu a incorporação encadeada de inovações nos modos de troca, principalmente a partir do século XIX.

As mudanças experimentadas pela dinâmica capitalista no fim do século XIX e início do século XX, quando, de acordo com as observações de Arrighi, os E.U.A. passam a abrigar a centralidade dessa dinâmica, deram-se, entre outros aspectos, no contexto de "uma grande revolução organizacional que deu origem a um grande número de corporações verticalmente integradas e burocraticamente administradas" (ARRIGHI, 1996: 290).

Contrariamente à fragmentação e à especialização da estrutura produtiva e comercial do regime de acumulação britânico que, dentre outras implicações, dificultava o aproveitamento das oportunidades de redução de custos através de um planejamento e integração das atividades e dos ramos, no regime norte-americano a integração vertical dos processos de produção e de troca constituiu-se numa de suas principais características (Idem, p. 291).

A necessidade de eliminar um regime de concorrência irrestrita entre unidades atomizadas conferiu importância às iniciativas que visavam bloquear a luta corporativa desregrada entre elas. Tais iniciativas acarretaram uma reestruturação empresarial que orientou a dinâmica econômica norte-americana à internalização de sub-processos de produção e comercialização que, por sua vez, submeteu a lógica econômica à ação administrativa e ao planejamento de longo prazo. Nesse contexto, o monopólio do espaço incluiu-se no mencionado rol de ações em direção a uma organização empresarial mais apurada, que visava uma regulação e/ou ampliação da reprodução do capital mais adequada.

O despertar de um mercado mundial único repercutiu, sobremaneira, na ampliação da indústria, dotando tanto a produção quanto o consumo, em todos os países, de um "caráter cosmopolita" (ARRIGHI, 1996: 259). Dessa maneira, à inaudita concentração de atividades e pessoas, correspondeu o surgimento e a inserção de inovações relacionadas ao consumo de massa, tais como grandes varejistas, agência de propaganda, empresas de vendas pelo correio, cadeias de lojas comerciais, que conferiram intensa complexidade à espacialização do capital. ${ }^{2}$

Essas transformações lançaram as bases para uma radical alteração nos modos de distribuição e troca no espaço-tempo do capitalismo norte-americano, que redundaram em novas configurações tanto da estrutura física quanto administrativa da atividade comercial e de serviços. Através delas talvez se possa explicar as razões pelas quais os $\boldsymbol{S}$. $\boldsymbol{C}(\mathbf{s})$. se desenvolveram originariamente nos EUA e não na Europa, uma vez que seu aparecimento está intrinsecamente articulado às demandas e possibilidades postas pela dinâmica econômica capitalista, no curso de sua história recente.

O surgimento e principalmente a difusão dos $\boldsymbol{S} . \boldsymbol{C}(\mathbf{s})$. nos Estados Unidos estão relacionados ao fenômeno de surgimento e expansão dos subúrbios que esteve intimamente relacionado ao advento do automóvel. ${ }^{3}$ As alterações nas áreas metropolitanas das cidades norte-americanas

2 Ao discutir a mudança de eixo ocorrida entre o ciclo sistêmico de acumulação inglês e o americano, Arrighi (1996: 247-248) destaca que, "As estratégias e estruturas de acumulação de capital que moldaram nossa época surgiram nos últimos 25 anos do século XIX. Originaram-se numa nova internalização dos custos da lógica econômica da iniciativa capitalista. Tal como o regime holandês levara os processos de acumulação de capital em escala mundial um passo adiante dos genoveses, ao internalizar os custos de proteção, e tal como o regime britânico os levara um passo além dos holandeses, ao internalizar os custos de produção, o regime norte-americano fez o mesmo em relação ao britânico, ao internalizar os custos de transação. [Nesse contexto,] A economia de velocidade proporcionada pela internalização dos custos de transação não se limitou às empresas manufatureiras, nem se originou nelas. As companhias ferroviárias tinham sido pioneiras na maioria das inovações organizacionais que iriam revolucionar a estrutura da acumulação nos Estados Unidos. Junto com essas inovações, houve uma reorganização completa da distribuição, através do surgimento de instrumentos de mercados de massa (grandes varejistas, agências de propaganda, empresas de vendas pelo correio, cadeias de lojas comerciais,) que internalizaram um grande volume de transações de mercado dentro de uma única empresa." (maiores detalhes consultar a obra do referido autor intitulada $O$ longo século XX. dinheiro, poder e as origens de nosso tempo. Rio de Janeiro: Contraponto; São Paulo: UNESP, 1996)

3 RAE (1965: 220) apud COHEN (Yehoshua S. Diffusion of an Innovation in an urban system: The Spread of Planned Regional Shopping Centers in the United States 1949 - 1968. Chicago: The University of Chicago - Department of Geography, 1972, p. 26), reconhece que, em algumas cidades norte-americanas, as estradas de ferro também contribuíram para com o 
incluíram não somente crescimento da população nos subúrbios, como também consideráveis transformações na estrutura residencial dessas áreas. ${ }^{4}$

O surgimento e a conseqüente expansão dos subúrbios, adicionado ao crescimento da população num contexto de aumento da renda per capita, acabaram por demandar bens e serviços especializados, obrigando o comércio varejista a se ajustar a uma nova realidade sócio-locacional. Inicialmente, as lojas de departamentos e os supermercados cumpriram este papel, aglomerando ramos de comércio e de serviços diversos. Porém, a crescente importância dos automóveis no cotidiano das pessoas, fez com que grandes áreas de terra, destinadas a abrigar estacionamentos, fossem incorporadas a esses estabelecimentos, especialmente naqueles localizados distantes das zonas residenciais.

Além disso, alguns empresários vislumbraram que a criação de grandes áreas destinadas à aglomeração de lojas comerciais variadas poderia satisfazer a demanda das novas fronteiras urbanas, delineadas pelo processo de aparecimento e expansão dos subúrbios norte-americanos. Em seguida, tais empresários decidiram estabelecer uma política de aluguel dessas áreas e, em contrapartida, além do espaço, passaram a oferecer não somente a manutenção do complexo como um todo, como também de outros serviços destinados tanto aos locatários quanto aos consumidores (COHEN, 1972: 27).

Essas inovações relacionadas tanto à estrutura quanto à dinâmica da atividade comercial nos EUA, podem ser compreendidas como elementos originários do que viriam a se constituir os futuros centros de comercialização e consumo no urbano capitalista. De posse de tais apontamentos, no que segue, são indicadas algumas das principais características que, uma vez incorporadas à atividade comercial, acabaram por redundar num novo objeto, o S.C.

Muitas das inovações que foram incorporadas à atividade comercial e que, de uma certa maneira, foram introduzidas nos $\boldsymbol{S} . \boldsymbol{C}(\mathbf{s})$. estão relacionadas à economia de aglomeração. ${ }^{5}$ Dentre elas é importante destacar a incorporação do princípio do auto-serviço (amplamente utilizado nos supermercados), o aumento nas dimensões físicas e a melhoria do ambiente interno das lojas, e, principalmente, o rateio entre muitos locatários de pequeno porte das atividades de propaganda e marketing. Pelo lado do grande capital envolvido com S.C., a concentração da propriedade de tais objetos nas mãos de poucos empresários. Combinando essas e outras inovações, o $\boldsymbol{S}$. $\boldsymbol{C}$. intensifica a obtenção de benefícios através da economia de aglomeração, racionalizando tal tendência seja através da necessidade de incrementar o planejamento (a concepção) das novas unidades a serem implementadas, seja através do desenvolvimento de técnicas direcionadas à otimização da gestão desse novo produto (idem, p. 28).

No Brasil, o surgimento e a expansão dos S.C(s). se deu no bojo das importantes transformações ocorridas na economia brasileira, a partir da implementação do que Gaeta (1992: 45) denominou de "'racionalidade' burguesa" (décadas de 1950 e 1960), ou seja, quando uma dinâmica de acumulação verdadeiramente capitalista teve condições de estabelecer-se no país. Tal dinâmica foi (e de uma certa maneira, ainda o é) caracterizada pelo significativo aumento de investimentos que contribuíram, enormemente, para a modernização do capitalismo brasileiro de um mercado pré-industrial em direção à sua monopolização. Nesse contexto, os investimentos dessa "nova" dinâmica de acumulação passam a determinar uma "nova" dinâmica do mercado consumidor, acarretando o desenvolvimento não só de novos produtos e tecnologias, como também de novas formas espaciais no espaço/cenário de nossas cidades.

Enfim, na atual etapa de maioridade do capitalismo no Brasil, o papel determinante na dinâmica de acumulação cabe aos investimentos que passam a determinar também a dinâmica do mercado consumidor. A transformação qualitativa havida no capitalismo brasileiro, e ligada à proeminência dos bens de produção e concentração dos recursos financeiros (bancos), foi capaz de criar, pela sua dinâmica própria, produtos novos mais eficientes no processo de acumulação e que penetraram em todas as áreas: no urbano, no comércio, no lazer, como o caso do "produto"

fenômeno da suburbanização. Porém, sua extensão, viabilizada pelo automóvel, indica a importância do mesmo na determinação do referido fenômeno.

4 COHEN, op. cit., 1972, p. $=25$.

5 A concentração das atividades econômicas no espaço, conhecida como economia de aglomeração, vem permitindo o contínuo aperfeiçoamento do binômio custos-lucros, proporcionando a crescente minimização dos custos e a crescente maximização dos lucros. Decorrem daí vantagens de natureza locacional que, no atual estágio do desenvolvimento capitalista, constituem aspectos importantes e determinantes à acumulação em proporções cada vez mais ampliadas. Nesse contexto, o $\boldsymbol{S}$. $\boldsymbol{C}$., enquanto um equipamento de comercialização e consumo planejado e executado por grandes empresas privadas, destaca-se como um exemplo bem acabado. 


\section{shopping center. ${ }^{6}$}

Pinta udi (1989: 80) ressalta que o surgimento dos S.C(s). no Brasil está articulado à intensa urbanização da economia e da população ocorrida a partir da década de 1960, e que concentrou-se no Sudeste brasileiro. Corroborando esta afirmação, a autora ainda destaca que os $\boldsymbol{S} . \boldsymbol{C}(\mathbf{s})$.

/.../ aparecem num momento em que a economia brasileira se desenvolve com a formação de monopólios, e os shopping centers representam esta tendência em nível das atividades comerciais varejistas, que não possuiam nenhum poder de mercado, exceto as grandes lojas e os supermercados [...]

Desde 1966, quando houve a inauguração do primeiro S.C. no Brasil, o Iguatemni, localizado na cidade de São Paulo, a denominada indústria de shopping centers vem experimentando significativo desenvolvimento.

De posse dessas noções, já se pode discorrer com mais detalhe sobre o fenômeno e a essência capitalista do $\boldsymbol{S} . \boldsymbol{C}$., segunda parte deste artigo.

\section{SHOPPING CENTER: O Fenómeno e sua Essência Capitalista}

O S.C. materializa a associação-combinação de diversos interesses. Via de regra, até o momento, é o setor privado que tem tido a iniciativa de sua construção. Constituído numa experiência, mas fruto da concentração de capital em poucas mãos [...] Os shopping centers não são obra do acaso (o primeiro pode até ter se privadas e de sua necessidade de reprodução contínua e ampliada, não importando se a sua origem é imobiliária, financeira ou comercial. $\mathrm{O}$ importante é que este grande capital construiu um local comercial de forma concentrada e encontrou uma maneira de reproduzi-lo melhor através da manutenção do espaço de vendas. $\mathrm{O}$ grupo empreendedor garante a exploração do shopping center através de uma administração que funciona junto ao empreendimento [...] Enquanto empresa de grande capital, ele surge no momento em que as condições de desenvolvimento do capitalismo necessitam do monopólio do espaço para a reprodução contínua e ampliada do capital, porque é através do poder de mercado que são equacionados os problemas da acumulação do capital [... $]^{7}$

Alguns aspectos podem e devem ser ressaltados a partir da citação acima:

1 $\left.^{\circ}\right)$ Pintaudi (1989) explicita a determinação de existência do S.C. na sociedade capitalista, articulando-a com a necessidade de reprodução crescente, contínua e ampliada do capital (acumulação). Na perspectiva da teoria social de Marx, isso vem a constituir um dos principais fatores a serem destacados, ou seja, a determinação econômica de uma dimensão material, na qual nosso cotidiano está imerso - o consumo de mercadorias. No momento atual, o S.C. constitui, no Brasil, a forma predominante de aglomeração da atividade comercial com vistas à sua reprodução ampliada.

$\mathbf{2}^{\circ}$ ) A concreção dessa forma de reprodução crescente, contínua e ampliada se dá, de um lado, através da aglomeração, em um mesmo local, de espaços destinados à atividade comercial e, de outro, pela sua monopolização. Essa indicação desvela a correlação entre uma determinação econômica - dada pelo capital nesse processo de reprodução-acumulação - e uma forma espacial; no caso em tela, o $\boldsymbol{S} . \boldsymbol{C}$.

A esse respeito, ou seja, o S.C. enquanto aglutinação e monopolização em um mesmo local de

6 GAETA, 1992:49.Conforme dados publicados no livro Shopping Centers Book (São Paulo: G\&A Editorial, s/d), com base em informações obtidas junto à Associação Brasileira de Shopping Centers ABRASCE, em agosto de 1998 havia 150 S.C(s). em funcionamento no Brasil, totalizando 3,3 milhões de metros quadrados de área bruta locável, ou cerca de 25.500 lojas. [...] O que caracteriza, entretanto a revolução tecnológica é a forma como foi estruturada a combinação de diversos interesses dos investidores no shopping center e dos comerciantes, permitindo a exploração adequada de economias de escala e a internalização de externalidades, especialmente aquelas relacionadas com os gastos em propaganda e promoção [...] (LANGONI, 1984:56)

7 PINTAUDI, 1989:24-27. Conforme já mencionado, a aglomeração constitui-se numa necessidade e decorrência do desenvolvimento da sociabilidade - do ser social - que, no caso em tela, é dada pelo capital. 
espaços destinados à atividade comercial, e também de serviços, Langoni (1984: 56) afirma que

[...] o aspecto marcante nos shopping centers não é o aparecimento de uma inovação de caráter físico (por ex., um equipamento), e sim os ganhos de eficiência associados a uma aparentemente realocação de fatores de produção [...]. A estrutura física do shopping centers $e ́$ num certo sentido, convencional, apenas utilizando de maneira inteligente todos os desenvolvimentos ocorridos na indústria da construção, de materiais e de equipamento imobiliário.

Como foi visto, tudo isso não aconteceu por acaso.

$3^{\circ}$ ) Outro aspecto que se considera importante de ser também destacado diz respeito à origem do capital que, concentrado, gera esse tipo de empreendimento. Pintaudi ${ }^{8}$ afirma que o importante é entender que o grande capital encontrou a maneira de melhor reproduzir-se, através da concentração da atividade comercial e seu respectivo controle, via monopólio do espaço de vendas. Em outra oportunidade, a autora, discutindo as fontes de financiamento dos S.C(s)., indica que [a]pesar de não contarmos com $34 \%$ da informação, fica bastante evidente a grande participação dos bancos na construção de Shopping Centers [...] As vantagens para o capital financeiro e imobiliário são grandes, já que o local de comercialização não é vendido e sim alugado, o que significa dizer que o(s) proprietário(s) do imóvel estarão sempre auferindo a renda de monopólio que é paga com o superlucro obtido pelo comerciante por estar naquele lugar de comércio $[\ldots]^{9}$

Entende-se que o que Pintaudi (1987) denomina de superlucro constitui-se, na realidade, na reapropriação de parte da parcela de mais-valia produzida socialmente, que anteriormente era destinada ao capital comercial. Trata-se aqui da parcela de mais-valia total produzida e apropriada na esfera do comércio (lucro comercial) que, em parte, é re-apropriada pelo empreendedor do S.C.

A tentativa de explicação desses entendimentos é a seguir indicada à luz de algumas formulações de Marx.

Considerar tais formulações enquanto orientação metodológica, não significa compreendê-las nos limites puros da economia. No presente estudo, tenta-se promover uma interação entre a economia propriamente dita, orientada pela lógica do capital, e a realidade extra-econômica no quadro da totalidade do ser social. Tal iniciativa tem por objetivo contribuir para a compreensão do capital enquanto uma relação social e, a partir daí, iluminar teoricamente algumas questões pertinentes ao nosso objeto de estudo, ou seja, o $\boldsymbol{S}$. $\boldsymbol{C}$. e suas repercussões na vida e na cidade.

Segundo Lukács (1979: 54), as observações de Marx não se limitaram a um mero objetivismo econômico. Através de um caminho objetivo-ontológico, são apresentadas as categorias econômicas em inter-relação dinâmica com o complexo de objetos e forças do ser social, no qual a figura central desse complexo é o homem (idem. ibidem).

$\mathrm{Na}$ formação sócio-econômica capitalista, o processo global da reprodução econômica é a síntese de três processos que se articulam, no real, num único processo, composto pelo ciclo do capital dinheiro (o capital monetário), o ciclo do capital produtivo (o capital industrial) e o ciclo do capital-mercadoria (o capital comercial). Todo o fim de um dos ciclos é, ao mesmo tempo, o início de um novo. A análise de tais ciclos - cuja articulação configura-se através de uma unidade de movimento materializada no processo global ininterrupto de reprodução social revela as proporções da sociedade capitalista. Tal revelação fornece elementos que possibilitam destruir a representação da sociedade capitalista enquanto objetividade destituída de significado social, permitindo compreendê-la enquanto uma relação social que, por sua vez, engendra formas de sociabilidade (idem: 58).

Nesse contexto, produção, consumo, distribuição, troca e circulação constituem-se as categorias mais gerais e fundamentais da economia. ${ }^{10}$ Imbricadas e interdependentes. Ou seja,

8 PINTAUDI, 1989.

9 PINTAUDI, 1987:41.

10 Segundo LUKÁCS (1979: 66), “[...] Na economia burguesa da época de Marx, essas categorias - como, por exemplo, produção e consumo - haviam sido em parte assumidas como idênticas, em parte contrapostas como excluindo-se reciprocamente, e em 
apresentando múltiplas e mútuas determinações, tais categorias evidenciam o traço fundamental de uma dialética materialista que, além de ter na produção seu momento predominante, ${ }^{11} \mathrm{em}$ nada se assemelha às teses simplificadoras e mecanicistas que, de uma certa maneira, têm vulgarizado e empobrecido a perspectiva marxiana.

Antes de dar início ao estudo do $\boldsymbol{S}$. C. à luz das categorias supracitadas, entendemos ser conveniente explicitar alguns conceitos já existentes sobre esse objeto, tratando de algumas de suas características mais importantes.

Pintaudi (1989: 27) aponta quatro elementos essenciais que constituem a base da existência de um S.C. São eles: a iniciativa do empreendimento que, conforme já exposto, no Brasil, tem sido de responsabilidade do setor privado; aluguel das lojas; combinação de lojas com pelo menos uma delas no papel de âncora ${ }^{12} \mathrm{e}$ a existência de áreas de estacionamento.

Segundo Hirschifeldt (1984: 28), para a Associação Brasileira de Shopping Centers ABRASCE, um S.C. caracteriza-se por ser

um centro comercial planejado, sob a administração única e centralizada e que: seja composto de lojas destinadas à exploração de ramos diversificados ou especializados de comércio e prestação de serviços, e que permaneça, em sua maior parte, objeto de locação; estejam os locatários sujeitos a normas contratuais padronizadas, visando à manutenção do equilíbrio de oferta e da funcionalidade, para assegurar, como objetivo básico, a convivência integrada; varie o preço de locação, ao menos em parte, de acordo com o faturamento dos locatários; e - ofereça a seus usuários estacionamento permanente e tecnicamente bastante.

De posse dessas noções preliminares acerca da importância e natureza das categorias que foram utilizadas nesta reflexão, parte-se para a realização da tarefa de explicitar a essência capitalista - do S.C. . Compreendendo-se a produção enquanto momento predominante e, a exemplo da forma utilizada por Marx (1997) na sua Contribuição à Crítica à Economia Política, analisa-se as inter-relações reais das categorias gerais da economia aos pares, iniciando-se pela relação mais complexa, a relação produção - consumo.

\section{Produção, Consumo e Shopping Center}

Produção, num determinado estágio do desenvolvimento histórico-social, significa a produção da existência material de indivíduos vivendo em sociedade.

Sem necessidade, não há razão para haver qualquer tipo de produção. Por sua vez, o consumo reproduz a necessidade (MARX, 1977: 220). O consumo confere um duplo caráter à produção pois,

[...] $1^{\circ}$, Somente pelo consumo o produto se torna verdadeiramente produto $[\ldots] 2^{\circ}, O$ consumo cria a necessidade de uma nova produção, por conseguinte a razão ideal, o móbil interno da produção, que é a sua condição prévia. O consumo cria o móbil da produção, lhe determina a finalidade. Se é evidente que a produção oferece, na sua forma material, o objecto de consumo, não é menos evidente que o consumo supãe idealmente o objeto da produção, na forma de imagem interior de necessidade, de móbil e fim. Cria os objetos da produção sob a forma ainda subjectiva. Sem necessidade não há produção. Ora o consumo

parte tratadas de modo a serem encaixadas em falsas hierarquias [...]"

11 Marx analisa as inter-relações reais começando pelo caso mais complexo, o da relação entre produção e consumo. Aqui, como também nas demais análises, o primeiro plano é novamente ocupado pelo aspecto ontológico, segundo o qual essas categorias embora apresentem entre si, mesmo singularmente, inter-relações freqüentemente muito intrincadas - são todas as formas de ser, determinações da existência; e, enquanto tais, formam por sua vez uma totalidade, só podendo ser compreendidas cientificamente enquanto elementos reais dessa totalidade, enquanto momentos do ser. Disso resultam duas conseqüências: por um lado, cada categoria conserva sua própria peculiaridade ontológica e a manifesta em todas as interações como as demais categorias (por isso, tampouco tais relações podem ser tratadas através de formas lógicas gerais, mas cabe compreender cada uma delas em sua específica peculiaridade); por outro lado, essas interações não são de igual valor, nem quando consideradas como pares nem tomadas em seu conjunto, mas ao contrário se impõe, em cada ponto, a prioridade ontológica da produção enquanto momento predominante [...] [Grifo nosso] (Idem: 67)

12 A título de simples menção cabe destacar que, no que se refere a este aspecto, não existe um consenso. Tal como vem sendo noticiado na imprensa escrita, alguns empreendedores de shopping center já admitem que tal característica não se constitui tão fundamental. 
Lukács (1979: 70) identifica nesse ato de suposição ideal, ou seja, de pré-ideação dos objetos da produção na esfera do consumo, a relação entre consumo e teleologia. ${ }^{14}$ Como vimos, na medida que o consumo cria a necessidade de uma nova produção e que, nesse contexto, supõe idealmente seu objeto, é através dele (consumo) que é definido o conteúdo da imagem anterior do mencionado objeto, como necessidade, como propensão e como fim, que põe em movimento e regula a produção. ${ }^{15}$

Cabe observar o desdobramento desse conteúdo tanto na produção de um $\boldsymbol{S} . \boldsymbol{C}$., ou seja, nos fatores que orientam sua concepção, quanto na sua reprodução, isto é, nas estratégias que orientam e ampliam sua vida útil depois de posto em operação.

A especificidade, a natureza e a função de um $\boldsymbol{S}$. C. requerem e inauguram uma série de saberes que, combinados, se não determinam um novo campo profissional, pelo menos ampliam outros já consolidados. Desenvolvendo-se ao longo de aproximadamente três décadas, desde o surgimento deste tipo de empreendimento, tais saberes visam ampliar, temporal e financeiramente, os ganhos de capital nele investidos.

Nesse sentido, em se tratando, antes de qualquer coisa, de um empreendimento imobiliário de grande porte e que por isso requer um volume considerável de recursos para sua realização, fica patente a exigência, desde a sua concepção, de todo um sofisticado conjunto de técnicas e estratégias de planejamento. A adoção de tal conjunto, de um lado, possibilita reduzir as margens de erro na tomada de decisão sobre o local e o tipo de empreendimento a ser construído, e, de outro, viabiliza a obtenção de parcelas crescentes de lucro após sua implantação. ${ }^{16}$

Vale também ressaltar que a instauração de novos saberes e técnicas acaba por demandar e determinar a formação de novos profissionais, cuja qualificação irá justamente criar, organizar e orientar a aplicação das ações convenientes, visando aproveitar ao máximo as oportunidades de valorização que o $\boldsymbol{S}$. $\boldsymbol{C}$. inaugura. Nunca é demais reforçar que embora tais oportunidades estejam mais claramente relacionadas à reprodução desse objeto, através da maciça aplicação de técnicas e/ou estratégias de marketing (na sua administração cotidiana assim como na organização de eventos e promoções), têm também sido desenvolvidas (e implementadas) técnicas e modelos de planejamento no processo de concepção e, num outro plano, da construção propriamente dita do empreendimento. A título de mera ilustração, são transcritos abaixo alguns fragmentos retirados de jornais de razoável expressão nacional que confirmam nossas observações.

Há uma estratégia de marketing para cada tijolo colocado na construção de um shopping. As empresas de consultoria avaliam o terreno, o sistema viário, os acessos e a melhor

13 MARX, 1977:219-220.

14 A história da realização do ser social, muitos já o disseram, objetiva-se através da produção e reprodução da sua existência, ato social que se efetiva no trabalho. Este por sua vez desenvolve-se pelos laços de cooperação social existentes no processo de produção material. Em outras palavras. o ato de produção e reprodução da vida humana realiza-se pelo trabalho. É a partir do trabalho, em sua cotidianidade, que o homem torna-se ser social, distinguindo-se de todas as formas não humanas. É por demais conhecida aquela passagem de O Capital, onde Marx diferencia o pior arquiteto da melhor abelha: aquele "obtém um resultado que já no início deste existiu na imaginação do trabalhador, e portanto idealmente. Ele não apenas efetiva uma transformação da forma da matéria natural; realiza, ao mesmo tempo, na matéria natural seu objeto, que ele determina, como lei, a espécie e o modo de sua atividade e ao qual tem de subordinar sua vontade." Em outras palavras, o ser humano tem ideado, em sua consciência, a configuração que quer imprimir ao objeto do trabalho, antes da sua realização. Isto ressalta a capacidade teleológica do ser social. É no trabalho, entendido como protoforma, como forma originária da atividade humana, ” que se pode demonstrar ontologicomente que o estabelecimento de uma finalidade é um momento real da efetiva realidade material [...] qualquer trabalho seria impossivel se não fosse precedido de uma tal colocação, determinandolhe o processo em todas as suas fases." (ANTUNES, 1988: 177)

15 [...] é através do consumo que é determinado o conteúdo essencial da posição teleológica que coloca em movimento e regula a produção. (LUKÁCS, 1979:70)

16 À guisa de demonstração do que se acaba de afirmar, é transcrito a seguir, o fragmento de um artigo publicado no Informativo ABRASCE de maio/abril de 1988. "Sem dúvida, estudos de viabilidade, quando feitos por empresa idônea e competente, reduzem substancialmente a margem de erro. Estes estudos hoje são tão rigorosos e feitos sobre base técnica tão precisa que, confrontados com os números reais do funcionamento do shopping, alguns anos depois, apresentam mínimas diferenças [...] Consideramos 3 os tipos de estudos: estudo diagnóstico de mercado, estudos preliminares de arquitetura e estudos de viabilidade econômicofinanceira. Todos se completam e são inter-dependentes, mas já houve casos em que a primeira etapa foi tão decisiva e conclusiva, que desaconselhamos o empreendedor a continuá-los, já que as estimativas mostravam, naquele caso, a completa inadequação do terreno para construção de um shopping. De todo modo, cumpridas estas etapas, que duram entre 120 a 150 dias, chegamos a um retrato bastante fiel do que deverá ser o shopping, que público atenderá, que perspectivas econômico-financeiras poderá ter, que volume de investimento deverá realizar e que retorno esperar. E aí começa outra etapa fundamental: a administração do shopping pronto, em sua primeira fase, de implantação.” Shopping Center: A importância dos estudos preliminares. Informativo ABRASCE, mar/abr, 1988. 
construção. Em seguida fazem uma pequena (sic) pesquisa sócio-econômica com futuros consumidores e uma análise detalhada do comércio existente na região. Comparam os hábitos de compra, o poder aquisitivo e o desejo do consumidor com o comércio local. Só então determinam o tipo de shopping que deve ser construído e qual a loja, chamada âncora, que servirá para atrair tanto consumidores quanto os lojistas $[\ldots]^{17}$

O aumento do número de shoppings no país está fazendo com que a função de superintendente desses empreendimentos fique cada vez mais cotada. Com a tarefa de administrar um complexo que se assemelha a uma cidade, esses "prefeitos" trabalham, em média 12 horas por dia e têm salário inicial de pelo menos Cr\$ 1,5 milhão por mês. $O$ mercado é relativamente novo, com poucos profissionais formados. Administrar um shopping significa trabalhar para três clientes: o empreendedor o lojista e o grande público que frequenta $[\ldots]^{18}$

A Encolpar - empresa do grupo Encol, que se dedica à construção e administração de shopping centers - está introduzindo um novo conceito nessa área: o par center João Bosco Ribeiro, diretor superintendente da empresa, explica que o projeto é baseado em 4 modernas tecnologias desenvolvidas a partir da instalação de elementos pré-fabricados. Esses projetos são destinados, principalmente, aos pólos e cidades do interior. "Baseados nesse conceito de shopping de vizinhança, já estamnos estudando 20 cidades, que englobam desde o Triângulo Mineiro, passando pelo interior de São Paulo, até o Centro-oeste”, revela João Bosco Ribeiro, diretor superintendente da Encolpar [...] Criada em 1989, a Encolpar além do Valparaíso [shopping que está sendo erguido na cidade satélite de Valparaíso] já administra outros investimentos no setor: O shopping Bouganvilie, em Goiania - no estilo do Fashion Mall - foi inaugurado emn setembro de 1990, com 120 lojas. No segundo semestre desse ano, é a vez do Liberty Mall, em Brasília [já em funcionanlento], que terá 82 lojas. ${ }^{19}$

Esse conjunto de técnicas e estratégias está, na realidade, articulado a uma racionalidade que consubstanciando-se no campo da gerência científica, visava a ampliação das possibilidades de acumulação, no contexto de um capitalismo eminentemente monopolista. Segundo Gaeta (1992: 50), embora tal racionalidade tenha se desenvolvido inicialmente voltada para a produção, acabou por penetrar

nos setores não diretamente produtivos, de forma a separar neles a concepção da execução. $O$ estudo do trabalho, de todas as suas formas e processos, deve agora ser impedido, não só aos trabalhadores, como também aos pequenos empresários, aos capitalistas não organizados e menos poderosos.

Interessante observar que, no bojo das importantes transformações experimentadas tanto pelo Estado quanto pela economia brasileira na década de 1960 (em especial a partir de 1964), consolidando um tipo de capitalismo de corte fundamentalmente monopolista, inaugura-se a entrada dos $\boldsymbol{S . C}(\mathbf{s})$. no país. Ou seja, as alterações sócio-políticas, burocrático-estatais e financeiro-industriais promovidas na mencionada década implicaram a determinação de uma nova dinâmica no mercado consumidor brasileiro (GAETA, 1992: 48-49). Os S.C(s). se inscrevem, enquanto novos objetos de consumo coletivo, na malha urbana resultante da nova interação entre acumulação e urbanização. Sua novidade determina novos saberes, técnicas assim como novas modalidades profissionais que articuladas e/ou imbricadas também se inserem na economia e no espaço da cidade.

Essa dialeticidade se espraia a outros setores da vida e da sociedade, reconfigurando-os. Nesse sentido, não menos importante constitui-se a determinação de novos padrões de sociabilidade urbana (hábitos, comportamentos, rotinas etc.) ${ }^{20}$ instaurados a partir da inserção dos $\boldsymbol{S}$.C(s). na

17 Marketing define cada tijolo das grandes obras. Jornal da Tarde, $1^{\circ}$ Caderno, 02.08.90, p. 27.

18 Surgem em SP os "prefeitos de shoppings". Folha de São Paulo, Emprego, 27.10.91, p.28.

19 Encolpar gera técnica para fazer shoppings. Jornal do Brasil, Negócios e Finanças, 26.06.91, p.10.

20 A noção de sociabilidade é aqui parametrizada pela relação social hegemônica no mundo atual, o capital. Nesse sentido, a sociabilidade (ou melhor, a forma capitalista de sociabilidade) encarna a gênese e todas as respectivas expressões relativas aos 
cidade.

Segundo Marx (1977: 220), a produção também confere um duplo caráter ao consumo, correspondendo aos seguintes aspectos:

[...] $1^{\circ}$, A produção fornece ao consumo a sua matéria, o seu objecto. Um consumo sem objecto não é consumo; neste sentido, portanto, a produção cria, produz, o consumo. $2^{\circ}$, Mas não é unicamente o objecto que a produção dá ao consumo [...] Tal como o consumo dava o retoque final ao produto como produto, a produção dá-o ao consumo. Em primeiro lugar o objecto não é um objecto geral, mas um objecto determinado, que deve ser consumido de forma determinada, à qual a própria produção deve servir de intermediária [...] Por conseguinte a produção determina não só o objecto do consumo, mas também o modo de consumo, e não só de forma objectiva, mas também subjectiva. Logo a produção cria o consumidor $3^{\circ}$, A produção não se limita a fornecer um objecto material à necessidade, fornece ainda uma necessidade ao objecto material. Quando o consumo se liberta da sua grosseria primitiva e perde o seu caráter imediato - e não o fazer seria ainda o resultado de uma produção que se mantivesse num estádio de primitiva rudeza -, o próprio consumo, enquanto instinto, tem como intermediário o objecto. A necessidade que sente desse objecto é criada pela percepção do mesmo. O objecto de arte - tal como qualquer outro produto - cria um público capaz de compreender a arte e de apreciar a beleza. Portanto a produção não cria somente um objecto para o sujeito, mas também cria um sujeito para o objecto [...]

Assim sendo, produção cria consumo!

No que se refere a essa última afirmação, Lukács destaca o caráter histórico-ontológico dessa relação (produção - consumo) no ser social, a partir do momento em que - como observa Marx (1977) - o consumo liberta-se da rudeza primitiva perdendo seu caráter imediato. Esse desenvolvimento explicita a tendência que as categorias do ser social adquirem na dinâmica de transformação de categorias naturais para, essencialmente, sociais. O consumo, antes um instinto necessário e fundamental à sobrevivência, encarna agora uma propensão mediatizada e modificada pelo objeto (LUKACS, 1979: 69).

Desse modo, a produção do $\boldsymbol{S}$.C., a partir de uma necessidade histórico-concreta posta pelo capital enquanto relação social, além de criar o objeto (S.C.) em si, determina um novo tipo de consumidor, através da criação de novos modos de consumir.

Nesse ambiente, o "novo" consumidor é totalmente imerso na lógica do capitalismo atual do super-consumo, que imprime um novo significado de coletividade, de socialização, agora forjadas pela intensa mercantilização e estetização.

O lugar, a estrutura e a dimensão de uma importante parcela do comércio das cidades reconfiguram-se radicalmente a partir da inserção dos $\boldsymbol{S}$. $\boldsymbol{C}(\mathbf{s})$. Sua natureza - agregadora de atividades, aliado ao seu porte e sua escala de aglutinação de diversos ramos do comércio e de serviços, tem transformado sobremaneira distintas parcelas do tecido e da vida urbana. Nesse sentido, a cidade já não se apresenta mais como cenário do encontro, da convivência. Sob os auspícios da lógica do superconsumo, seus espaços públicos — ruas, praças — são agora reinventados, privatizados. De um lado, a territorialidade dos vendedores ambulantes e os dos camelôs que engendram a face mais "popular" desse universo e, de outro, os $\boldsymbol{S} . \boldsymbol{C}(\mathbf{s})$, que materializam sua versão mais requintada e, de certa maneira, excludente.

$\mathrm{Na}$ atual cadência do mundo e da vida contemporânea, onde, no processo de dissociação entre ideação e realidade, à (des)parametrização da primeira corresponde a falsificação da segunda, o S.C. constitui-se no peculiar cenário que engendra e abriga uma nova sociabilidade. Entorpecidas pelo fulgor do mundo da mercadoria que, com seu brilho ofuscante, dissimula a perversidade da lógica capitalista, especialmente quando se trata das cidades do terceiro mundo, novas gerações são forjadas. Os fragmentos coletados na imprensa escrita que são abaixo indicados, ilustram tal constatação:

Moradora da Urca, Mariana Troianelli, 15 anos, faz ponto no Rio Sul, onde chega de

modos de vida forjados pelas e/ou nas relações sociais de produção. Para maior detalhamento consultar HUNT, E. K. História do Pensamento Econômico. Rio de Janeiro: Editora Campus Ltda., 1987, pp.25-26. 
carro com chofer ou a pé mesmo. O negócio é estar lá, entre as amigas e os "brotos". "Também gosto de shopping porque sou supergastadeira ", diz ela, despachadíssima. Além de ver vitrines, Mariana gosta de morey boogie e tem pavor da escola. "Não gosto de ir a aula quando tem onda. Nem muito de estudar Aliás ficar nos shoppings à tarde não é programa de CDF mesmo ", conclui. ${ }^{21}$

Pelo menos três vezes por semana o bancário Fábio Nicolau, 24 anos, vai ao Plaza Shopping. Terminado o expediente, sai apressado do banco em que trabalha. no Centro de Niterói, para ir a lojas experimentar roupas. Não é nenhuma mania yuppie. Para ele e os amigos Luciano Oliveira, 19 anos, e Ricardo Moraes, 20, ambos auxiliares de cartório, provar roupas é apenas um pretexto [...] Assim como ele, 10 entre 10 niteroienses elegeram o Plaza como o melhor shopping da cidade. Com razão. Na escassez de opções de lazem mesmo quem não oferece o máximo em termos de atrações leva vantagem $[\ldots]^{22}$

Na nova ala do terceiro andar do Shopping Center Iguatemi tem sido desde sua inauguração, há um mês, o pano de fundo para o crescimento de um novo grupo de frequentador local. São os "iguaboys ", jovens com idade entre 14 e 18 anos de ambos os sexos que vão ao Iguatemi no mínimo duas vezes por semana e no máximo sete [...] "A gente vem aqui mais para um "relax", olhar as garotas e encontrar a turma", diz René Lasserre Filippi, 15 [...] O traje do jovem assíduo do Iguatemi é quase um uniforme ao qual se permitem apenas algumas variações de cores $[\ldots]^{23}$

A instauração de novas sociabilidades também pode ser percebida nas diversas estratégias que as administrações dos $\boldsymbol{S} . \boldsymbol{C}(\mathbf{s})$. têm lançado mão com o objetivo não somente de atrair novos consumidores, como também de ampliar a incorporação desse objeto no cotidiano das cidades. Para tanto, através de um conjunto de sofisticadas técnicas de propaganda e marketing, têm sido introduzidas diversas inovações que vão desde campanhas promocionais veiculadas nos diversos meios de comunicação de massa (jornais, revistas e televisão), até a incorporação de funções que, em alguns casos, acabam por demandar a inclusão de novos espaços que até então eram inimagináveis no programa arquitetônico de um S.C.

Chamar um shopping center de templo é injustiça. Estes prédios de concreto, belas vendedoras e neon não são apenas um convite ao gasto. Paradoxalmente, a falta de dinheiro também leva gente ao shopping. O mais incrivel, no entanto, é que o que tinha tudo para ser um programa de índio pode se transformar em uma boa opção de lazer. Ilhas de segurança cercadas de estacionamentos próprios por todos os lados, alguns destes centros comerciais mantém - entre lojas, lojas e mais lojas - salas de teatro, cinema e exposição. Mas a programação cultural dos shoppings não se restringe apenas a espaços tradicionais que podem ser encontrados em outros pontos da cidade. Uma happy hour, por exemplo, não poderia acontecer em outro lugar além de um shopping center. De lanchonetes a restaurantes, passando por soverterias e lojas de doces, lugares para se comer não faltam dentro de um shopping. Antes e/ou depois de um programa besta, nada melhor do que comer uma besteira. Na pior das hipóteses, o cidadão duro e suarento vai poder curtir o ar refrigerado de um desses tão temíveis antros de consumo. Siga o roteiro desta página e descubra que qualquer um pode ir ao shopping neste fim de semana, se divertir e sair de lá sem ter deixado mais de um salário mínimo para comprar uma camiseta de butique. ${ }^{24}$

A geração shopping center não precisa se distanciar de um templo do consumo para se casar O espaço ecumênico que ocupa o lugar de uma loja na nova ala poderá ser reservado para cerimônias, segundo a administração. As regras não foram definidas, mas a central de

21 Que juventude é essa? Eles vivem no shopping center, um lugar tão seguro quanto a praça de antigamente. In: Jornal do Brasil, Revista de Domingo, 24.04.88, p.31

22 Paquerar e badalar: O Plaza Shopping se transforma no grande centro de lazer da cidade. Jornal do Brasil - Caderno Niterói, 22.10 .88$, p.4.

23 De cabelo espetado, 'Iguaboy'faz do Iguatemi um palco de paquera. Folha de São Paulo. Cidades, 23.10.88, p.C-2.

24 Shopping também pode ser cultura. Jornal do Brasil, Caderno B, 02.03.90, p.2. 
atendimentos ao consumidor já pode encaminhar a solicitação. O espaço ecumênico ocupa um dos 133 módulos de lojas da nova ala. Tem 28 cadeiras saídas de antiquários, além de bancos nas laterais. E decorado com plantas, mas não tem icones religiosos. Entre as vantagens do lugar para um casamento estão a segurança dos convidados e a facilidade de acesso ao shopping e de estacionamento. Quem pensa em festa conta ainda com 11 restaurantes do shopping. Amanhã de manhã haverá no espaço uma cerimônia ecumênica com o guesche budista Jonnayang, o padre Albino Schwnger, o rabino Henry Sobel e o pastor presbiteriano Gérson Correia. ${ }^{25}$

Estamos inaugurando o shopping do ano 2000. Agora. O Morumbi Shopping - o shopping de São Paulo - surpreende mais uma vez. Está vendo este monumento de arquitetura de vanguarda? [o anúncio mostra a foto da nova ala do shopping] é uma homenagem a São Paulo: um novo espaço cultural de $700 \mathrm{~m}^{2}$, coberto com pirâmides de vidro, capaz de acomodar uma orquestra sinfônica e uma grande platéia. Nele você vai se sentir no coração de uma grandiosa obra de arte. E é por ele que você entra no Morumbi Shopping. Lá dentro você vai encontrar novas áreas, novas lojas e novas surpresas para somar a tudo que já existia. Uma das novidades mais saborosas é a praça do mercado. Se você é uma dona de casa simplesmente preocupada com o jantar; ou um executivo que aprecia preparar pessoalmente uma bouillabaisse com peixes confiáveis, esse é o melhor dos mundos. Inspirada no antigo mercado municipal central, a praça do mercado traz para o shopping alimentos frescos e selecionados, deliciosamente expostos sob arcos e vitrais construídos por artesãos. Até o horário é diferente: a partir das 9 da manhã durante a semana, das 9 às 13 horas aos domingos. Percorrendo outros pisos, mil facilidades para sua vida. O Morumbi Shopping é suficiente para suprir as necessidades mais diferentes de todo tipo de pessoa. Não é preciso ser um garoto com vontade de rodopiar numa pista de gelo. Se você for um empresário, em breve poderá reunir seus gerentes no centro de convenções para um seminário. Se você for um homem que de repente precisa de uma camisa lavada e passada, ali está uma lavanderia. Porque além de suas compras, agora no Morumbi Shopping é possivel malhar na academia de ginástica, estudar um idioma, saborear um tour gastronômico e até meditar num templo ecumenico. O shopping do ano 2000 tem tudo isso, desde novembro de $1992 .^{26}$

Pelo que se pode perceber, há uma tendência à incorporação aos $\boldsymbol{S}$. $\boldsymbol{C}(\mathbf{s})$. de diversos tipos de serviços e comércio que inicialmente não eram neles encontrados. Há inclusive, a incorporação do que, apesar de ser considerado uma infração dos costumes sociais, tinha, até então, a rua como seu principal locus de atividade, isto é, a prostituição. $\mathrm{O}$ fragmento apresentado a seguir ilustra o que estamos dizendo, destacando a centralidade e, portanto, importância do $\boldsymbol{S}$. $\boldsymbol{C}$. no cotidiano de algumas de nossas cidades.

Um recente estudo feito por pesquisadores do Centro Brasileiro para Infância e Adolescência (CBIA) mostra que os pólos irradiadores da prostituição de classe média são os shopping centers - há lojas em que as meninas são arrebanhadas para clientes endinheirados. Segundo a pesquisadora Lúcia Pinto Leite, a prostituição de menores da classe média, muitas vezes com o objetivo de conseguir dinheiro para pagar o colégio ou comprar uma roupa, é um dos aspectos mais polêmicos do problema. ${ }^{27}$

Tal incorporação (de uma gama enorme de serviços e/ou comércio e/ou atividades) pode acarretar uma espécie de esterilização do espaço em torno desses objetos, esterilização esta que merece estudos mais detalhados. O que se considera importante ressaltar é que esta tendência tem sido muito bem articulada aos interesses do capital, ampliando suas possibilidades/oportunidades de acumulação. Tal fato torna-se ainda mais gritante quando correlacionados aos diversos problemas urbanos enfrentados em algumas de nossas cidades (miséria, violência,

25 Shopping inaugura ala com templo, "feira" e academia. Folha de São Paulo, Cotidiano, 17.11.92, p3-3.

26 Anúncio veiculado pelo Morumbi Shopping na Folha de São Paulo, Cotidiano, 21.11.92, p.3-6.

27 Meninas de classe média se prostituem em shoppings. O Globo, Grande Rio, 19.08.91, p.1 1 
engarrafamentos, etc.), problemas estes que são, senão totalmente retirados de cena, razoavelmente amenizados.

Os shopping centers de São Paulo estão ampliando suas instalações para diversificar o atendimento a seus usuários e alguns deles estão investindo mais recursos em seus serviços. $O$ shopping center Eldorado (zona oeste) inaugurou uma ala inteiramente dedicada a serviços de primeira, segunda e terceira necessidades. Na "Alameda de Serviços" há Lavanderias, caixas eletrônicos, cabine de foto instantânea, loja para animais, despachante, chaveiro, loja de consertos de antigüidades e de recuperação de brinquedos, onde se repara desde braços de bonecas até motores de carrinho de autorama. Embora o Eldorado seja o primeiro a reunir num só local serviços que antes ficavam perdidos pela cidade, tê-los integrados ao conjunto de lojas sempre foi uma preocupação dos shoppings paulistas. Dentro da idéia de expansão - uma palavra que hoje faz parte do marketing de todo shopping center , deve haver pelo menos um serviço. [...] É função do shopping dar ao cliente a possibilidade de numa única visita saciar todas as necessidades" (sic), diz o superintendente do shopping Morumnbi, Wilson Spinelli. [...] São Paulo é uma cidade grande. Normalmente, para mandar a roupa para a lavanderia, sacar ou depositar dinheiro e passar no correio, uma pessoa tem que visitar três lugares diferentes. Dentro da filosofia do shopping cumpre a nós resolver esses problemas", diz a gerente de marketing do Eldorado, Eleonora de Souza Ramos Pereira. A escolha dos serviços que integram um shopping não é aleatória e deve combinar com o estilo do consumidor de cada um deles. [...] Além de ter um posto do Detran - onde se pode, por exemplo, requisitar gratuitamente uma relação das multas do carro -, um correio, outro da Telesp, uma sapataria, uma lavanderia e uma clínica médica $[\ldots]^{28}$

A magnitude dessa progressiva e indiscutível tendência de inserção dos $\boldsymbol{S} . \boldsymbol{C}(\mathbf{s})$. na vida urbana tem implicado a criação de um aparato jurídico que, mesmo tendo como objetivo proporcionar maior conforto e segurança aos usuários que os freqüentam, de uma certa maneira, acaba por também reforçar o destaque, a importância e a centralidade desse objeto geográfico no cotidiano das cidades. Os trechos abaixo transcritos constituem-se importantes exemplos dessa indicação.

A prefeita Luiza Erundina determinou ontem, através de decreto publicado no "Diário Oficial ", que todos shopping centers de São Partia devem instalar; em 180 dias, ambulatórios ou pronto-socorros $[\ldots]^{29}$

A classe artística carioca está comemorando desde já a conquista de novos espaços: projeto de lei do vereador Sérgio Cabral (PSDB) determina que, a partir de agora, os shopping centers construidos no Rio, com área acima de 30 mil metros quadrados, deverão ter no mínimo uma sala de teatro e uma de cinema. Apresentado pela primeira vez em 85, foi aprovado pela Câmara Municipal e está para ser sancionado pelo prefeito Marcelo Alencar; apesar dos protestos da Associação Brasileira de Shopping Centers. O projeto de lei aprovado pela Secretaria Municipal de Cultura - determina entre outras coisas que as salas de cinema e teatro - localizadas obrigatoriamente no pavimento térreo e com livre acesso às áreas externas do centro comercial - deverão ter capacidade mínima de 250 e 350 lugares respectivamente, com locais especiais para deficientes fisicos $[\ldots]^{30}$

Tal como se pode verificar, a análise que é aqui empreendida mostra que para além de um simples equipamento destinado à comercialização, ou seja, para além de uma mera materialidade destinada a abrigar a função de comércio de mercadorias, o $\boldsymbol{S}$.C., compreendido como vetor de

28 Se tudo correr conforme espera Valdezir Oliveira de Carvalho, 46, proprietário da Aval Empreendimentos, o quilómetro 72,5 da rodovia Castelo Branco vai se transformar em desvio obrigatório para todos os proprietárias rurais acostumados a percorrer o circuito Sorocaba-Avaré. É ai que a Aval planeja erguer o Agroroad Shopping, que vai abrigar 84 lojas, praça de alimentação, posto de serviços e até uma praça de rodeios. A idéia é atrair os pequenos sitiantes, fazendeiros de fim-de-semana, proprietários de haras e moradores das cidades vizinhas, potenciais freqüentadores do shopping. Castelo Branco vai ter shopping rural. Folha de São Paulo, Agrofolha, 14.07.92, p.5-6.

Shoppings apostam nos serviços rápidos e ampliam suas instalações. Folha de São Paulo, Cidades, 01.04.91, p.C-1.

29 Shoppings terão que instalar ambulatórios. Folha de São Paulo, Cotidiano, 10.05.91, p.4-4.

30 Teatro e cinema conquistam espaço. Jornal do Brasil, Cidade, 11.10.89, p.6. 
acumulação e, por conseguinte, fazendo parte do conjunto de elementos e processos constituintes da relação social capitalista, pode ser estudado a partir de diversos ângulos.

Dando prosseguimento a estas notas, trata-se, a seguir, das demais categorias e suas relações com o S.C.

\section{Produção, Distribuição, Troca, Circulação e o Shopping Center}

Nesta seção, o S.C. é analisado a partir da relação entre produção, distribuição, troca e circulação de mercadorias, no contexto da sociedade capitalista. Assim sendo, segundo Marx (1985: 165),

[...] a circulação das mercadorias [ou seja, a troca considerada na sua totalidade] é o ponto de partida do capital. A produção de mercadorias e o comércio, forma desenvolvida da circulação de mercadorias, constituem as condições históricas que dão origem ao capital. $O$ comércio e o mercado mundiais inauguram no século XVI a moderna história do capital.

Além disso, em outra oportunidade, o autor esclarece a relação entre a produção e a troca, compreendendo esta última enquanto um momento da primeira, na medida em que, antes de mais nada, na própria produção ocorrem trocas tanto de atividades quanto de capacidades. Dessa maneira, é válido dizer que a troca constitui-se, manifestamente, um dos momentos da produção (MARX, 1977: 227). Num outro momento, através da troca é que o produto acabado será fornecido ao mercado para seu consumo.

Essas observações explicitam duas diferentes modalidades de troca. Assim sendo, de um lado, uma modalidade de troca que se efetua no momento da produção e, de outro, a troca que se realiza na esfera do consumo imediato, e é nesta modalidade que se concentra esta seção, ou seja, é na esfera do consumo imediato que se localiza o $S$. C.

Para estudá-la, há que se refletir sobre a maneira pela qual o capital comerciante de mercadorias estrutura-se; quais as demandas físicas para sua operação e de quais estratégias de que ele se utiliza para sua conseqüente reprodução.

Antes, porém, vale indicar alguns apontamentos acerca das condições necessárias e fundamentais para que o processo de troca de mercadorias seja efetivado. São elas: (1) para haver troca é necessário haver divisão de trabalho. (2) A troca e a produção necessitam ser igualmente privadas no contexto da existência de uma reciprocidade entre os indivíduos, ou seja, que um só se aposse da mercadoria do outro, através de um ato comum voluntário. (3) A intensidade, a extensão, assim como o modo pelo qual é realizada a troca de produtos, são determinados pelo grau de desenvolvimento e pela estrutura da produção, ou seja, a troca está diretamente compreendida na produção ou por ela determinada.

Ao longo da história, no contexto da progressiva complexidade assumida pelo ser social, a troca surge e se desenvolve na medida em que é viabilizada a produção de um excedente. Sua regularidade indica algum desenvolvimento das forças produtivas, resultante dos aperfeiçoamentos efetuados nos meios de produção, isto é, da incorporação de melhorias e inovações técnicas no processo produtivo. Dessa maneira, o nível de desenvolvimento das forças produtivas de uma sociedade determina a quantidade e a qualidade das mercadorias disponíveis. Finalmente, em quarto lugar, outro aspecto de fundamental importância refere-se à necessidade de existência de uma forma equivalente socialmente válida. No processo de desenvolvimento das forças produtivas, impõe-se a eleição de determinada mercadoria como meio universal de troca, cristalizada na forma dinheiro, através da qual se trocam mercadorias de diferentes possuidores e comparam-se valores.

Como o processo de reprodução abrange tanto a esfera da produção quanto da circulação, é exigido que, tanto numa quanto noutra, haja responsáveis (capitalistas e/ou assalariados), os agentes da produção e os agentes da circulação. A crescente diversificação e complexidade da produção capitalista irão requerer a especialização desses agentes, implicando sua separação.

Neste contexto, terá que haver um investimento na esfera da circulação das mercadorias, constituindo-se assim o capital comercial de mercadorias. Este, materializa-se, de um lado, na forma de uma coleção de mercadorias que é lançada ao mercado para converter-se em dinheiro; de outro, na forma dinheiro que, já situada no mercado, está para se converter em mercadoria. 
Dessa maneira, na circulação, enquanto uma fase do processo de reprodução do capital produtivo, o capital-mercadoria e suas metamorfoses correspondentes - ou seja, a conversão deste em capital dinheiro e vice-versa - constituem, conseqüentemente, fase de todo o processo de reprodução do capital. Além disso, quando essa função - de capital-mercadoria - que está no processo de circulação adquire autonomia em virtude da divisão do trabalho, torna-se função específica de um determinado tipo de capitalista, convertendo-se em capital comercial (MARX, 1984b: 310). ${ }^{31}$ Desse modo, em outra oportunidade, esse mesmo autor destaca que:

[o] capital comercial portanto nada mais é do que o capital-mercadoria que o produtor fornece e tem de passar por processo de transformação em dinheiro, de efetuar a função de capital-mercadoria nó mercado, com a diferença apenas de que essa função, em vez de ser operação acessória do produtor; surge como operação exclusiva de variedade especial de capitalistas, os comerciantes, e adquire autonomia como negócio correspondente a um investimento especifico. ${ }^{32}$

Função particular de um capital também particular que, em virtude da divisão social do trabalho, acaba por tornar-se função própria de determinada categoria de capitalistas, convertendo-se o capital-mercadoria em capital comercial de mercadorias. As duas passagens de Marx, respectivamente (1984a: 113 e 134), indicadas a seguir, esclarecem e complementam o que se quer demonstrar:

O modo capitalista de produção supõe produção em grande escala e necessariamente venda em grande escala, venda portanto ao comerciante e não ao consumidor isolado. [...] $O$ funcionamento do capital mercantil dá origem a uma ilusão. Mas, sem entrar em pormenores, fica desde já evidente: uma função, em si mesma improdutiva, embora necessária à reprodução, se transforma, com a divisão do trabalho, de uma tarefa acessória de muitos em tarefa exclusiva, especializada de poucos, não muda ela, com isso, de caráter Um comerciante apenas (considerado aqui mero agente da conversão formal das mercadorias, somente comprador e vendedor) pode, com suas operações, encurtar o tempo de compra e o tempo de venda de muitos produtores (MARX, id. ibid, 113).

As transformações da forma mercadoria para a forma dinheiro e vice-versa constituem os dois processos de circulação destas formas distintas assumidas pelo capital. A primeira transformação, ou seja, da mercadoria em dinheiro, é a realização da mais-valia incorporada à mercadoria. A segunda, a metamorfose do dinheiro em mercadoria, constitui-se no retorno do valor-capital à figura de seus elementos de produção (134).

Ao longo de seu tempo de circulação, o capital não funciona como capital produtivo, não produzindo, portanto, mercadoria e mais-valia. No processo de circulação há apenas mudança de forma de uma mesma massa de valor. Portanto, configurando-se como um momento de improdutividade do capital, o tempo de circulação limita o tempo de produção, o que, em outras palavras, significa limitação do processo de produção de mais-valia.

A primeira transformação - mercadoria - dinheiro (m-d) - constitui a etapa mais problemática devido à inexistência de garantia de venda. A segunda transformação - dinheiro - mercadoria (dm) - implica a incorporação de determinados elementos ao processo produtivo e, por toda a sorte de motivos e circunstâncias, pode demandar um tempo de circulação maior ou menor. Isto, além de indicar a dimensão e a importância da esfera da circulação de mercadorias no processo de produção, sugere também rotações diferenciadas do capital industrial e do capital comercial.

$\mathrm{Na}$ indústria, a massa de mais-valia produzida e, portanto, de lucro está diretamente relacionada ao número de rotações do capital nessa esfera. Contudo, a realização desta massa de mais-valia produzida depende do capital comercial. Dessa maneira, não somente os agentes da produção como também os agentes responsáveis pela circulação irão envidar todos os esforços possíveis na busca de maior produtividade do capital. Nesse contexto, a autonomização do capital comercial impõe-se enquanto uma necessidade no sentido de promover uma economia de custos. Os agentes, tanto da produção quanto da circulação, orientados por essa determinação ontológica

31 Importante ressaltar que antes mesmo do surgimento da produção industrial, o capital comercial, assim como o monetário e a renda fundiária, conservaram, por longo tempo, uma existência autônoma.

32 MARX, K. 1984b e LUKÁCS, 1977: 65. 
do próprio sistema, lançarão mão de toda sorte de artifícios com o objetivo de atingir esse fim.

Assim sendo, serão incorporados ao processo de valorização de capital, tanto no âmbito da produção quanto do consumo, não somente os procedimentos relacionados à gerência da mão-deobra (taylorismo, fordismo, etc.) quanto as inovações técnicas que se estendem inclusive à organização e à racionalização do ambiente construído dos espaços destinados às referidas atividades. Não é difícil perceber que o $\boldsymbol{S}$. $\boldsymbol{C}$. materializa uma delas.

Discutindo a relação entre gerenciamento dos $\boldsymbol{S} . \boldsymbol{C}(\mathbf{s})$. e as transformações do espaço urbano, Gaeta (1992: 45-59) destaca que a gerência científica, impulsionada pela dinâmica da acumulação capitalista, é encontrada nos novos empreendimentos imobiliário-comerciais, especialmente quando se considera os aspectos ligados tanto à sua administração quanto à sua organização interna.

O investimento de um capital, na esfera da circulação de mercadorias, permite ao capital industrial uma redução de tempo e, de certa maneira, de despesas pertinentes à circulação. Na realidade, a redução de tais despesas ocorre na medida em que um mesmo agente responsável pela circulação venha vender as mercadorias produzidas pelos diversos agentes da produção, concentrando e racionalizando, através dos ganhos de escala, todo o aparato destinado e necessário à circulação.

$\mathrm{Na}$ circulação são consumidos tempo e força de trabalho para efetuar a conversão m-d e d-m, gastos - em parte improdutivos - necessários à produção. Tal como Marx (1984a: 136) indica,

[...] [n]o processo de circulação, tem que ser gasta, para a mera conversão de forma, certa quantidade de força de trabalho, de tempo de trabalho. Mas isto se patenteia agora dispêndio suplementar de capital; parte do capital variável tem agora de ser empregada na compra e venda dessas forças de trabalho que funcionam na circulação. Esse adiantamento de capital não cria produto nem valor. Diminui de quantidade correspondente a amplitude em que funciona produtivamente o capital adiantado. E como se parte do produto se transformasse numa máquina que compra e vende o produto restante. Essa máquina faz desconto no produto. Não funciona no processo de produção, embora possa diminuir a força de trabalho etc. gasta na circulação, representando apenas parte dos custos de circulação.

Os custos de circulação podem ser resumidamente indicados como o conjunto formado pelos custos estritos de circulação, pelos custos de conservação e pelos custos de transporte (MARX, 1984a: 132-155). Os custos estritos de circulação compreendem o tempo de compra e venda de mercadorias, a contabilidade e o dinheiro. São determinações histórico-concretas postas pelo capital na sua dinâmica de acumulação crescente e ampliada.

O tempo de compra e venda constitui-se tempo que o capitalista leva para realizar estes atos, envolvendo trabalho, inclusive assalariado, que não cria nenhuma espécie de valor. Implica, como já foi destacado, em custos necessários ao processo de reprodução do capital.

O caráter social da produção capitalista, que por sua vez, inclui a circulação de mercadorias, demanda em grau crescente e ampliado, a necessidade de controle não somente da produção, como também da circulação de mercadorias. Dessa maneira, a contabilidade impõe-se como atividade de fundamental importância, absorvendo tanto força, quanto meios de trabalho (trabalho materializado nas diversas formas de utensílios e equipamentos necessários a seu desempenho tais como móveis, material de escritório, etc.) (MARX 1984a: 136). ${ }^{33}$

Por outro lado, está claro que a forma de existência das mercadorias, ou seja, sua vida enquanto valores de uso, determina certos limites à circulação. Genericamente falando, é sabido que quanto maior o número de rotações do capital industrial em seu conjunto. maior será a massa de mais-valia produzida e, conseqüentemente, a massa de lucro.

Nesse sentido, concentrar a atividade comercial é, sem dúvida nenhuma, uma das formas de reprodução do capital, pois a produção capitalista gera, em sua dinâmica de acumulação crescente e ampliada, um número tão grande de mercadorias que, necessariamente, tem que engendrar novas formas de realização destas últimas. Outrossim, como foi mencionado anteriormente, na sociedade capitalista, a necessidade humana está subsumida à necessidade do capital, e é neste

33 Talvez seja o caso de também inserir a propaganda neste conjunto, na medida que ela constitui-se importante quesito na ampliação do consumo, criando necessidades junto ao público. 
contexto que se desenrola a sociabilidade do mercado; isto é, a determinação pelo capital das formas de realização que melhor lhe convierem.

Desse modo, novos arranjos para a realização da mercadoria são requeridos, sendo o S.C. um deles, no qual tem se conformado e desenvolvido a complexa sociabilidade dos dias em curso.

É através da monopolização do espaço, no caso daquele destinado à atividade comercial, que o grande capital se utiliza para equacionar e maximizar suas oportunidades de acumulação.

Como vimos anteriormente, Pintaudi (1989: 41) detectou que uma das razões da expansão dos S. C(s)., estaria relacionada à vantagem obtida a partir da obtenção da renda de monopólio, através do aluguel do local de comercialização, paga com o lucro obtido pelo comerciante que se instala no $\boldsymbol{S}$.C. . A compreensão deste aspecto ilumina a essência e o fenômeno do $\boldsymbol{S}$.C., constituindo-se de fundamental importância para aqueles envolvidos com a temática da comercialização e do consumo de mercadorias na atualidade.

\section{À Guisa de Conclusão}

Indiscutivelmente o $\boldsymbol{S}$. $\boldsymbol{C}$. constitui-se uma nova forma arquitetônico-urbana. A escala e a importância que este objeto vem adquirindo na atualidade têm contribuído, sobremaneira, para a alteração da vida e da paisagem das cidades.

Combinando os interesses dos investidores e dos comerciantes, concentrando e explorando adequada e racionalmente as diversas vantagens relacionadas à economia de escala ${ }^{34}$ e de aglomeração, ele (re)define a centralidade, (re)valoriza as áreas de seu entorno e engendra novas possibilidades, oportunidades assim como constrangimentos aos habitantes da cidade capitalista, delineando, nos dias em curso, novos padrões sociais e culturais, aqui resumidos ao termo sociabilidade (do capital).

O S.C. pode ser considerado muito mais do que a simples justaposição de um local de vendas com equipamentos destinados ao lazer e à recreação. Na realidade, este objeto tem transformado $\mathrm{o}$ ato de consumir em atividade de lazer. Nesse sentido, seus empreendedores lançam mão de diversas estratégias que têm por objetivo prioritário atrair todo e qualquer tipo de consumidor que, nesse ambiente asséptico, de uma forma ou de outra, será compelido ao consumo.

Sua existência, tanto nas cidades dos países capitalistas hegemônicos quanto nos países periféricos, não anula a permanência de outras formas de ambiente construído destinado ao consumo; quais sejam as galerias e os centros comerciais, assim como o tradicional comércio de rua. Ressalta-se, porém, que a crescente importância dos S.C(s). no cenário das cidades representa, ainda que por um momento, uma alternativa estratégica de vida e sociabilidade tendo em vista o incremento das contradições do capitalismo no seio das aglomerações urbanas.

Através desse novo objeto de comercialização e consumo, o capital empreendedor do $\boldsymbol{S}$.C. se valoriza em três momentos, a saber: (1) na construção propriamente dita do equipamento, como capital da indústria da construção civil, extraindo mais-valia diretamente dos trabalhadores que a produziram; (2) na forma de valorização da renda da terra ${ }^{35}$, através do aluguel composto; $;^{36}$ e (3) na venda de serviços especializados em administração de $\boldsymbol{S}$. $\boldsymbol{C}$.

O estudo do $\boldsymbol{S}$.C., muito mais do que simplesmente refletir sobre a dinâmica do comércio varejista que se concretiza através dele, abre novas possibilidades de estudo sobre as novas formas de dominação capitalista nas diversas esferas da vida cotidiana.

O que se pretendeu neste trabalho foi, através da compreensão marxiana das categorias produção, consumo, distribuição, troca e circulação de mercadorias, contribuir para com os estudos sobre o comércio no contexto atual da produção material capitalista.

Talvez, a crescente privatização da vida urbana contemporânea, se inscreva no conjunto de desdobramentos da atual dinâmica capitalista que, na contramão das tentativas pretéritas de expansão generalizada de produção e mais valia, tem se constituído, predominantemente, numa expansão excludente. Sem sombra de dúvida, o S.C. representa um veículo singular nesse processo.

34 LANGONI, 1984: 56-69.

35 MARX, 1984:887-896.

36 GAETA, 1992: 51. 
Resumo: Este trabalho trata do shopping center na perspectiva da teoria social de Marx. Pretende-se aqui desvelar o fenômeno e a essência capitalista deste importante objeto (arquitetônico — urbano) inscrito no conjunto de elementos e processos relacionados às alterações da dimensão espaço-tempo na reorganização contemporânea do capital que tem, sobremaneira, transformado as cidades.

Palavras Chave: Capitalismo; shopping center; Urbano.

Abstract: This paper deals with shopping center from Marx's social theory perspective. The main task here is to reveal the phenomena and the capitalist essence of such urban — architectonic object as an important element linked to the contemporary re-organization of capitalist development that, in turn, has dramatically affected urban process.

Key Words: Capitalism; shopping center; Urban.

\section{Bibliografia}

ANTUNES, Ricardo. 1982. Classe Operária, Sindicatos e Partido no Brasil: um estudo sobre a consciência de classe, da Revolução de 30 até a Aliança Nacional Libertadora. São Paulo: Cortez e Editora Ensaio: Autores Associados.

ARRIGHI, G. 1996. O Longo Século XX: dinheiro, poder e as origens de nosso tempo. Rio de Janeiro: Contraponto; São Paulo: UNESP.

BIENENSTEIN, G. 1993. Acumulação de Capital e Espaço Urbano: O Exemplo do Shopping Center. Rio de Janeiro: UFRJ: Tese de Mestrado submetida ao Instituto de Geociências da Universidade Federal do Rio de Janeiro.

1997. Reestruturação Econômica e Produção do Ambiente Construído: Algumas Indagações. In: $7^{\circ}$ Encontro Nacional da ANPUR. Anais... Recife. pp. 773 - 796. Espaços Metropolitanos em Tempos de Globalização: Um Estudo de Caso do Rio de Janeiro. 2000. Rio de Janeiro: UFRJ. Tese de Doutorado submetida ao Instituto de Pesquisa e Planejamento Urbano e Regional da Universidade Federal do Rio de Janeiro.

COHEN, Yehoshua S. 1972. Diffusion of an Innovation in an Urban System: The Spread of Planned Regional Shopping Centers in the United States 1949 -1968. Chicago: The University of Chicago - Department of Geography.

GAETA, Antônio Carlos. 1992. Gerenciamento dos Shopping Centers e Transformação do Espaço Urbano. In: Shopping Centers: Espaço, Cultura e Modernidade nas Cidades Brasileiras. S. Paulo: Ed. UNESP.

HARRIS F. \& O'BRIEN Larry. 1988. Retailing: shopping, society, space. London: David Fulton Publishers.

HIRSCHFELDT, R. V. 1986. Shopping Center, O Templo do Consumo. Rio de Janeiro: Associação Brasileira de Shopping Centers, Biblioteca Técnica.

HOBSBAWM, E. 1995. A Era dos Extremos: O Breve Século XX 1914-1991. São Paulo: Companhia das Letras.

JACKSON, Edgard L. \& JOHNSON, Denis B. 1991. Geographic Implications of Mega-Malls, with Special Reference to West Edmonton Mall. In: The Canadian Geographer, vol.35, $n^{\circ}$ 3, Fall/Automne.

LANGONI, C. Geraldo. 1984. Shopping Centers no Brasil. In: Shopping Centers Aspectos Jurídicos.(Coord. José Soares Arruda e Carlos Augusto da Silveira Lôbo. São Paulo: Ed. Revista dos Tribunais.

LUKACS, G. 1979. Ontologia do Ser Social: Os Princípios Fundamentais de Marx. São Paulo: Livraria Editora Ciências Humanas.

MARCONDES, C. 1986. Quem Manipula Quem? Poder e Massas na Indústria da Cultura e da Comunicação no Brasil. Petrópolis, RJ: Vozes.

MARX, Karl. 1977. Contribuição à Crítica da Economia Política. Lisboa: Editorial Estampa. 1984. O Capital. Livro 3, vol. VI. Rio de Janeiro: Editora Civilização Brasileira, 1985. O Capital: Livro 1, vol. 1. São Paulo: Difel.

MÉSZAROS, 1. 1995. Beyond Capital. London: Merlin Press.

PINTAUDI, Silvana M. 1987. Os Shopping Centers Brasileiros e o Processo de Valorização do Espaço Urbano. In: Boletim Paulista de Geografia. São Paulo: Associação dos Geógrafos Brasileiros. $\mathrm{N}^{\circ} 65$. 
M. 1989. O Templo da Mercadoria: estudo sobre os Shopping Centers do Estado de São Paulo. São Paulo: USP. Tese de Doutorado submetida ao Departamento de Geografia da faculdade de Ciências e Letras da Universidade de São Paulo.

PINTAUDI, S. M \& FRÚGOLI JR. H. 1992. Shopping centers: Espaço, Cultura e Modernidade nas Cidades Brasileiras. São Paulo: Editora da Universidade Estadual Paulista.

PINTO, Isabel Aparecida 1991. A Dimensão do Consumo e o Papel dos Shopping Centers na Sociedade Capitalista. In:: II Simpósio de Geografia Urbana. Repensando a Cidade e o Urbano, Rio Claro, SP. p. 18. Shopping Centers Book. S/d. São Paulo. 